\title{
Assessment of Oral Health Care Delivery System in Greater Noida Using Five A's Model
}

BACKGROUND: Access to dental health services refers not only to utilization but also to the extent by which the utilization is judged as per the professional norms using five independent dimensions of accessibility, availability, accommodation, affordability and acceptability.

AIM: The aim of the study is to assess the dental services utilization among population of Greater Noida using Five A's model. MATERIALS AND METHOD: The study was conducted in Dental College in Greater Noida. This cross-sectional study was carried out on the 200 subjects using convenient sampling on the patients visiting dental OPD.A self-administered structured questionnaire in English and Hindi language was used. Data was entered in the Microsoft excel sheet and analysed using SPSS (version 20.0). RESULTS: Mean level of access to dental services in the study population was 60.3.Corresponding figures for affordability, availability, accessibility, accommodation and acceptability were $55.2 \pm 12.1,57.1 \pm 12.8,60.75 \pm 14.7,61.75 \pm 8.7,58.65 \pm 11.4$ respectively. CONCLUSION: According to the results of our study, the level of access to dental care services is not very good with family income, location and level of education being the determinants of this access.

KEYWORDS: Oral Health Care Delivery, Accessibility, Affordability, Availability, Acceptability

\section{INTRODUCTION}

Good health is the condition where both our body as well as our mind are functioning properly. Over the years, evidence-based information has suggested that the health of our mouth, mirrors the conditions of our body as a whole. Dental disorders have affected mankind from time immemorial, and man has always tried to fight with the disease process by various methods available to them. Oral health is the reflection of our general well-being, therefore, oral health is also an essential part of the public health but which is often neglected in health care policies. The poor ability to access the health services is strongly associated with factors such as poverty, mismanagement of services, and unavailability of facilities. ${ }^{1}$ Access to dental services not only refers to utilization but also to the extent by which the utilization is judged as per the professional norms using five independent dimensions of availability, accessibility, accommodation, affordability and acceptability. ${ }^{2}$

Affordability is determined by how the charges of the provider relate to the ability of client and his/her and willingness to pay for the concerned services. Availability reflects the extent to which the provider has the requisite resources to meet the needs of the patient. Accessibility is the geographical accessibility, which is determined by how easily the client can physically reach the location of the provider. Accommodation refers the extent to which the provider's operation is organized in ways that meets the preferences and constraints of the client. ${ }^{3}$ And finally, acceptability describes the extent to which the client is comfortable with the more immutable characteristics of the provider, and vice versa. These characteristics include the age, gender, social class, and ethnicity of the client and provider, as well as the type of coverage and diagnosis of the client. ${ }^{3}$

The World Health Organization has identified the inverse care law as one of the common shortcomings of health care delivery which suggests that the availability of good health care tends to vary inversely with the need for the same in the population that is being catered. India, being one of the biggest democracies in the world, with a population of more than a billion is rapidly developing and making great progress in information technology, finance and living standards. In spite of these, it is very discouraging that very few people believe in regular dental care. ${ }^{4}$ Greater Noida is one of the emerging township in western Uttar Pradesh which is still under development. It has mixed culture of population and the utilization of dental services is 
very low. Aim of the present study was to assess the dental services utilization among population of Greater Noida using Five A's model.

\section{Objectives:}

1. To assess the oral health care delivery system using 5 A's model.

2. To assess the dental services utilization among population using 5 A's model.

\section{MATERIALS AND METHOD}

The study was conducted in Dental College in Greater Noida. Ethical clearance was taken from the Institutional Review Board before starting the study. Verbal consent was taken from the individuals who were willing to participate in the study. A Pilot study was conducted on 20 subjects to check the feasibility of the study and validity of questionnaire was also checked. This cross-sectional study was carried out on the 200 subjects using convenient sampling on the patients visiting dental OPD who met the following inclusion and exclusion criteria:

\section{Inclusion Criteria:}

- Patients attending dental college and hospital were included in the study.

- Subjects willing to participate.

\section{Exclusion Criteria}

- Subjects who were uncooperative.

- Subjects hiding the facts regarding their income, education and occupation were excluded from study.

- Those who did not give verbal consent were excluded from the study.

Scheduling: The average time for the each study subject was approximately 20-25 minutes. The entire study was carried out over the period of two months.

Data Collection: A self-administered structured questionnaire in English and Hindi language was used. The data for the study was recorded on pretested questionnaire (Moosazadeh $\mathrm{M})^{2}$ by personal face to face interview of the study subjects by a single interviewer. Questionnaire included general information regarding socio-demographic characteristic of the study subjects including name, age, gender, income, occupation, education, number of family members. It also included view about general and dental health, attitude regarding family dental health, monthly budget for dental health, dental attendance pattern, main reason for visit, treatment received, experience with previous dental visit and attitude towards dental treatment and preferred place for dental service utilization, cost of dental treatment.

Statistical Analysis: Data was entered in the Microsoft excel sheet and analysed using SPSS (version 20.0). Descriptive methods and analytical tests (chi square test and multivariate linear regression models) were used. Chi square test was applied to analyse the factors for availability, accessibility, accommodation, affordability and acceptability of dental services. Multivariate Analysis of demographic factors with affordability and overall level of access was done. $p$ value of 0.05 was considered to be statistically significant.

\section{RESULTS}

Out of total 200 study subjects, 140 were males $(70 \%)$ and 60 were females (30\%). $83 \%$ of the study population lived in peri urban area of Greater Noida. It was found in the study that $31.5 \%$ of the subjects were illiterate whereas $17 \%$ were having high school certificate and only $11.5 \%$ were graduate or postgraduate (Table 1 ).

It was found that $64.3 \%$ of males had insurance or health scheme where as $43 \%$ females had insurance or health scheme which was found to be highly significant (Table 2).

It was seen in the study that $48.6 \%$ males and $30.0 \%$ females had got no treatment due to high cost which was found to be highly statistically significant. It was also found that the $17.1 \%$ of the males refused for dental prosthesis due to high cost where as $16.1 \%$ females refused dental prosthesis due to high cost(Table 3 ).

It was found that affordability to dental services was significantly higher among males living in urban areas and who had done graduation or higher degree with monthly income level between INR 31,591-47,262. While availability was significantly associated with location of residence, education status. It was seen that Accessibility was significantly associated with location of residence, education status and monthly income of the study population. Accommodation was seen significantly associated with location and education and whereas acceptability was also significantly associated with location of residence, education status and monthly income of the study population(Table 4 ). 


\begin{tabular}{|c|c|c|c|}
\hline Variable & & $\mathbf{n}$ & \%age \\
\hline \multirow{2}{*}{ Gender } & Male & 140 & 70.0 \\
\hline & Female & 60 & 30.0 \\
\hline \multirow{2}{*}{ Location } & Urban & 34 & 17.0 \\
\hline & Periurban & 166 & 83.0 \\
\hline \multirow{7}{*}{ Education } & $\begin{array}{c}\text { Profession or } \\
\text { Honours }\end{array}$ & 22 & 11.0 \\
\hline & $\begin{array}{c}\text { Graduate or } \\
\text { post } \\
\text { graduate }\end{array}$ & 23 & 11.5 \\
\hline & $\begin{array}{l}\text { Intermediate } \\
\text { or post high } \\
\text { school dip }\end{array}$ & 24 & 12.0 \\
\hline & $\begin{array}{l}\text { High school } \\
\text { certificate }\end{array}$ & 34 & 17.0 \\
\hline & $\begin{array}{c}\text { Middle } \\
\text { school } \\
\text { certificate }\end{array}$ & 20 & 10.0 \\
\hline & $\begin{array}{l}\text { Primary } \\
\text { school } \\
\text { certificate }\end{array}$ & 14 & 7.0 \\
\hline & Illiterate & 63 & 31.5 \\
\hline \multirow{7}{*}{$\begin{array}{l}\text { Income (in } \\
\text { INR) }\end{array}$} & $>126,360$ & 2 & 1 \\
\hline & $\begin{array}{l}63,182- \\
126,356\end{array}$ & 61 & 30.5 \\
\hline & $47,266-63178$ & 10 & 5 \\
\hline & $31,591-47262$ & 38 & 19 \\
\hline & $18,953-31589$ & 45 & 22.5 \\
\hline & $6327-18949$ & 38 & 19 \\
\hline & $\leq 6323$ & 6 & 3 \\
\hline
\end{tabular}

Table 1. Demographic Characteristics of Study Subjects

\begin{tabular}{|c|c|c|c|}
\multicolumn{2}{c}{ Yes } & No & p value \\
\hline MALE & 90 & 50 & \\
& $64.3 \%$ & $35.7 \%$ & $\begin{array}{c}\text { o.oo1 } \\
\text { (Significant) }\end{array}$ \\
\hline FEMALE & 26 & 34 & \\
& $43.3 \%$ & $56.7 \%$ & \\
\hline
\end{tabular}

Table 2. Percentage of subjects with Insurance or Health Scheme

According to multivariate linear regression model significant association was there between total level of access with education status and location of residence. Moreover affordability was significantly associated with location of residence (Table 5).
Mean level of access to dental services in the study population was found to be 6o.3. Corresponding figures for affordability, availability, accessibility, accommodation and acceptability were $55.2 \pm 12.1,57.1 \pm$ $12.8,60.75 \pm 14.7,61.75 \pm 8.7,58.65 \pm 11.4$ respectively

\section{DISCUSSION}

Present study indicated that the access to dental services was not at a promising status. The same was true for each of five components of access as described by 5 A's model. The analysis also indicated that the acceptability of dental services was related to education level of participants which was in accordance with study done by Moosazaadeh $\mathrm{M}$ et.al ${ }^{2}$, Davidson and Anderson ${ }^{5}$, Bhushan $\mathrm{P}^{1}$ who indicated that education was significantly associated with use of dental services among populations. Availability dimension received the (57.1).This indicates that the people believed there were not enough resources, to meet their needs which is not in accordance with study done by Moosazaadeh $\mathrm{M}$ et.al ${ }^{2}$,Ravindranth NS et al. ${ }^{6}$ Accessibility dimension received (60.75) indicates geographic accessibility which refers to easiness of patient's physical access to the providers location which was in accordance with the study done by Moosazaadeh $\mathrm{M}$ et al. ${ }^{2}$ Affordability dimension of access received (55.2) indicates that for a significant number of studied people inability to pay for dental services was an obstacle in front of using dental services which was in line with the study done by Moosazaadeh M et al. ${ }^{2}$, Casey et al. ${ }^{7}$ and Wallace BB et al. ${ }^{8}$ who also found that inability to pay the cost of dental care contribute to lower use of dental services. The accommodation of dental services is appropriate. It means that the dentists working hours and way of organizing service providers is acceptable for service recipients which was in accordance with the study done by MoosazaadehMet.alzand not in accordance with Ravindranath $\mathrm{NS}^{6}$ who found negative attitude towards dentist's waiting time.

\section{CONCLUSION}

According to the results of our study, the level of access to dental care services is not very good with family income, location and level of education being the determinants of this access. The major limitation of our study was that population of Greater Noida is mainly the rural population where the people are either illiterate or have only basic education, therefore more extensive studies needs to be conducted to have proper 


\begin{tabular}{|c|c|c|c|c|c|c|c|c|}
\hline & FILLING & DENTAL & тоОтн & $\begin{array}{l}\text { SURGICAL } \\
\text { SERVICES }\end{array}$ & GUM & NO & MORE & P VALUE \\
\hline & & PROSTHEIS & EXTRACTION & & INFECTION & TREATEMENT & THAN & \\
\hline & & & & & & & ONE & \\
\hline \multirow[t]{2}{*}{ MALES } & o & 24 & 6 & 2 & o & 68 & 40 & \multirow{4}{*}{$\begin{array}{c}0.001 \\
(\text { SIGNIFICANT })\end{array}$} \\
\hline & $.0 \%$ & $17.1 \%$ & $4.3 \%$ & $1.4 \%$ & $.0 \%$ & $48.6 \%$ & $28.6 \%$ & \\
\hline \multirow[t]{2}{*}{ FEMALES } & 4 & 10 & 6 & 4 & 6 & 18 & 12 & \\
\hline & $6.7 \%$ & $16.7 \%$ & $10.0 \%$ & $6.7 \%$ & $10.0 \%$ & $30.0 \%$ & $20.0 \%$ & \\
\hline
\end{tabular}

Table 3. Dental Services Refused due to High Cost of Treatment

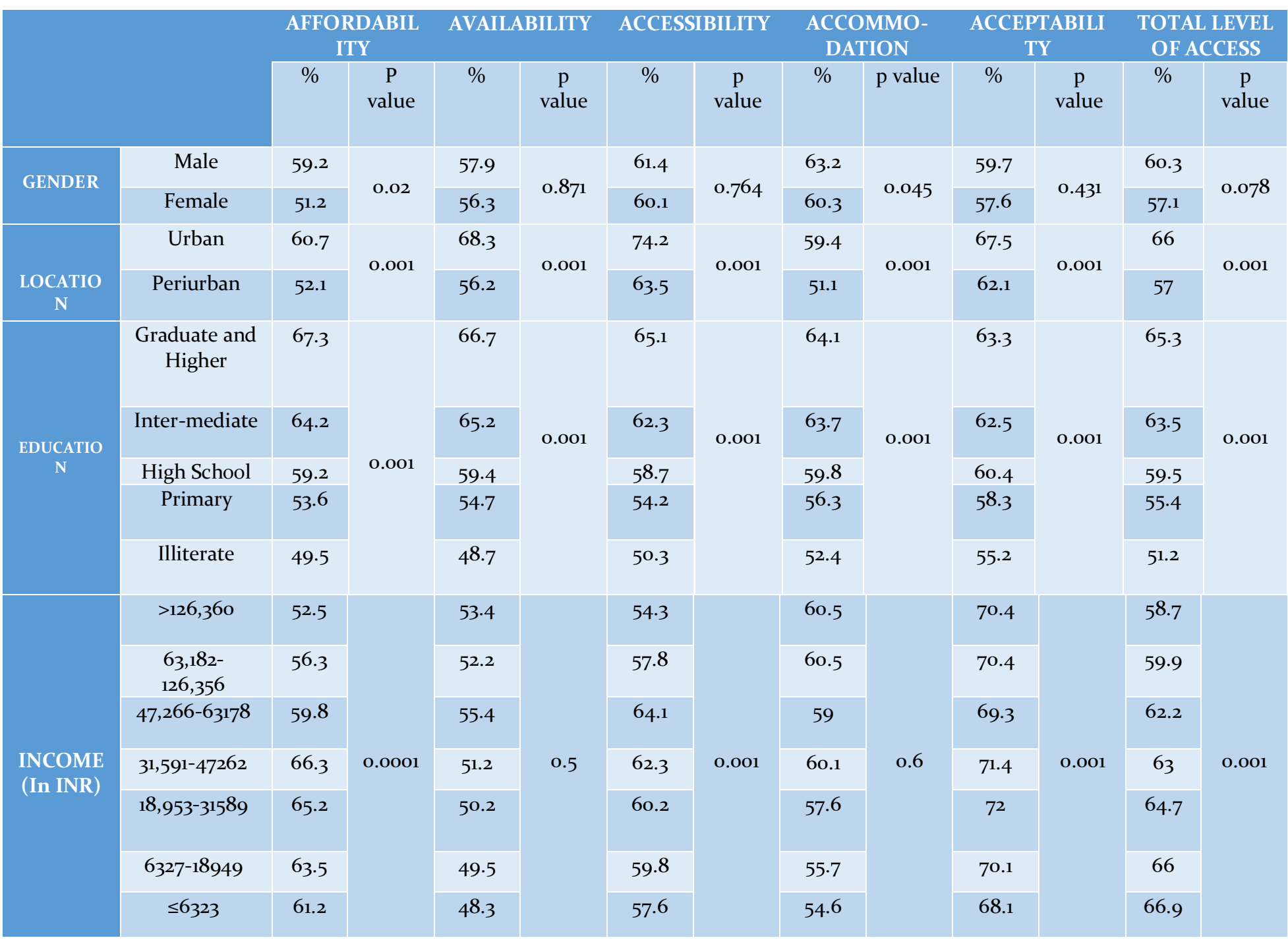

Table 4. Status of Access Varieties Aspects to Dental services by Variables Studied 


\begin{tabular}{|c|c|c|c|c|c|c|c|}
\hline & \multicolumn{3}{|c|}{ AFFORDABILITY } & \multicolumn{3}{c|}{ LEVEL OF ACEESS } \\
\hline & $\mathrm{B}$ & $\mathrm{p}$ value & $\mathrm{CI}$ & $\mathrm{B}$ & $\mathrm{p}$ value & $\mathrm{CI}$ \\
\hline GENDER & 2.6 & 0.01 & $1.3-4.9$ & 0.008 & 0.87 & $1.4-1.4$ \\
\hline LOCATION & 2.3 & 0.001 & $4.02-1.1$ & 1.03 & 0.03 & $1.8-0.09$ \\
\hline EDUCATION & 2.1 & 0.01 & $1.2-4.03$ & 0.4 & 0.04 & $0.6-1.7$ \\
\hline
\end{tabular}

Table 5. Multivariate Analysis of Demographic Factors with Affordability and Overall Level of Access

understanding of the utilization of dental services by the population.

\section{RECOMMENDATIONS}

1. The dental community should be sensitive to patients' occupations as a marker for limited dental care access and unmet dental care needs.

2. State funding should be earmarked for the development of oral health care services targeting worker groups (and their families)reporting the highest levels of unmet dental care needs and significant barriers to receiving dental care.

\section{REFRENCES}

1. Bhushan P, Arora G, Agrawal R, Kumar MK, Barde D. Affordability of population towards dental care in Mathura City-A household survey. Global Journal Of Medicine And Public Health 2012; 1(6):1-8.

2. Moosazadeh M, Amiresmaili M, Karimi S, Arabpoor M, Afshari M. Appraisal of Access to dental services in south east of Iran using 5A's model. Materia Sociomedica. 2016;28(3):196-200.
3. McLaughlin CG, Wyszewianski L. Access to Care: Remembering Old Lessons. Health Services Research 2002;37(6):1441-3.

4. Kakatkar G, Bhat N, Nagarajappa R, Prasad V, Sharda A, Asawa K, et al. Barriers to the Utilization of Dental Services in Udaipur, India. J Dent (Tehran) 2011;8(2):819.

5. Davidson PL, Anderson RM. Determinants of dental care utilization for diverse ethnic and age groups. Adv Dent Res. 1997;11(2);254-62.

6. Ravindranath NS, Manikyam A. Public attitude towards dentists and dental services in Bangalore city, India. J Indian Assoc Public Health Dent; 2014:12(2):100-5.

7. Casey M, Gestur D, Ira M. Access to dental care for rural low income and minority populations 2004: Rural Health Research Center. Division of Health Services Research and Policy, School of Public Health, University of Minnesota. 2004

8.Wallace BB, Macentee MI. Access to dental care for low-income adults: perceptions of affordability, availability and acceptability. J Community Health 2012;37(1):32-9.
Source of support: Nil, Conflict of interest: None declared
Cite this article as:

Nissar I, Gupta B, Kotia P, Raina K, Monga A. Assessment of Oral Health Care Delivery System in Greater Noida Using Five A's Model. Int Healthc Res J. 2019;3(9):309-313. https://doi.org/10.26440/IHRJ/0309.12308

\section{AUTHOR AFFILIATIONS: $\left({ }^{*}\right.$ Corresponding Author)}

1. PG Student

2. *Professor (ORCID ID: https://orcid.org/oooo-0oo3-3864-2474)

Department of Public Health Dentistry, ITS Dental College, Greater Noida, UP, India

3. Senior Lecturer, Department of Public Health Dentistry, Manav Rachna Dental College, Faridabad, India 